\title{
STABILITY CONSTANTS FOR SOME DIVALENT METAL ION/ CROWN ETHER COMPLEXES IN METHANOL DETERMINED BY POLAROGRAPHY AND CONDUCTOMETRY
}

\author{
L. CHEN $^{\mathrm{a}}$, M. BOS*, P. D. J. GROOTENHUIS ${ }^{\mathrm{b}}$, A. CHRISTENHUSZ, \\ E. HOOGENDAM, D. N. REINHOUDT ${ }^{b}$ and W. E. VAN DER LINDEN \\ Laboratory of Analytical Chemistry, Department of Chemical Technology, Twente \\ University of Technology, P.O. Box 217, 7500 AE Enschede (The Netherlands)
}

(Received 26th May 1987)

\section{SUMMARY}

Stability constants in methanol at $25.0^{\circ} \mathrm{C}$ were evaluated for the complexes of the divalent cations $\mathrm{Ca}^{2+}, \mathrm{Ni}^{2+}, \mathrm{Zn}^{2+}, \mathrm{Pb}^{2+}, \mathrm{Mg}^{2+}, \mathrm{Co}^{2+}$ and $\mathrm{Cu}^{2+}$ with the macrocyclic polyethers 15-crown-5 (15C5), 18-crown-6 (18C6), dicyclohexyl-18-crown-6 (DC18C6) and dibenzo-24-crown-8 (DB24C8). The $\log K$ values of the $1: 1$ complexes were generally in the range $2.1-4.2$, which is low in comparison to the values of the corresponding crown ether/alkali metal ion complexes. $M_{2} L$ complexes were observed for the systems $\mathrm{Pb}^{2+} / 18 \mathrm{C} 6, \mathrm{~Pb}^{2+} / \mathrm{DC} 18 \mathrm{C} 6, \mathrm{Ca}^{2+} / \mathrm{DC} 18 \mathrm{C} 6$ and $\mathrm{Cu}^{2+} / \mathrm{D} 18 \mathrm{C} 6$, whereas $\mathrm{ML}_{2}$ complexes were found for $\mathrm{Ca}^{2+} / 18 \mathrm{C} 6$ and $\mathrm{Cu}^{2+} / 18 \mathrm{C} 6$. Within the series of complexes studied, there was no clear relationship between cation diameter and hole size.

Interest in the complexation of divalent cations by macrocyclic polyethers originates from work in this department on the complexation of neutral molecules like urea [1], alcohols [2] and related polyfunctional molecules. It was shown that the thermodynamic stability of complexes of crown ethers with neutral guest molecules is low in comparison to the stabilities of the corresponding complexes with cationic guests $[3,4]$. Therefore, attempts were made to increase the interactions between host and neutral guest by using a co-complexed electrophilic cation $\left(\mathrm{Li}^{+}\right)$capable of polarizing the guest. This concept has resulted in the construction of macrocyclic polyethers that complex both an electrophilic cation and a neutral guest molecule. Recently, the crystal structure of a complex of a 2,6-pyridyl crown ether with $\mathrm{Li}^{+}$and two molecules of urea [5] was reported. Such systems can serve as models for complicated biological systems, such as metalloproteins.

Divalent (transition) metal cations are known to coordinate various types of ions and neutral molecules [6] and are therefore potentially interesting electrophiles. In order to design host molecules that co-complex a divalent

\footnotetext{
aPresent address: Department of Chemistry, Anhui University, Hefei, Anhui, People's Republic of China.

${ }^{b}$ Present address: Laboratory of Organic Chemistry, Twente University of Technology.
} 
cation together with a neutral molecule, it is important to know more about the thermodynamics of complexation of macrocyclic polyethers with divalent cations. This binding of divalent cations by macrocyclic polyethers has received little attention in comparison to the complexes of such polyethers with alkali metal ions, as can be seen from the review of Izatt et al. [7]. Thermodynamic data on the complex formation for divalent cations were obtained calorimetrically [8-11]. For some of the transition metal ions, no significant heat effect was observed, which means either that no complexes are formed or that the enthalpy of complexation is very small. In this work, conductivity [12] and polarographic [13, 14] methods were used to study the effects of ring size and substituents on the ring on the strength of the complexation of divalent transition metals $\left(\mathrm{Co}^{2+}, \mathrm{Ni}^{2+}, \mathrm{Cu}^{2+}\right)$ and main-group metals $\left(\mathrm{Ca}^{2+}, \mathrm{Mg}^{2+}, \mathrm{Zn}^{2+}, \mathrm{Pb}^{2+}\right)$. These methods are particularly suitable for these types of metal ion; they are not restricted to complexformation reactions with a significant heat effect, but are also applicable to complex formations driven by entropy effects.

\section{EXPERIMENTAL}

\section{Chemicals}

The crown ethers dicyclohexyl-18-crown-6 (DC18C6) and dibenzo-24crown-8 (DB24C8) were used as received (Merck). 15-Crown-5 (15C5) and 18-crown-6 (18C6), also from Merck, were purified before use to remove acidic impurities: $15 \mathrm{C} 5$ was distilled under vacuum and $18 \mathrm{C} 6$ was purified by preparing its acetonitrile complex and then removing the acetonitrile under vacuum [15].

The supporting electrolytes used in the polarographic studies were tetraethylammonium iodide (TEAI; Janssen Chimica) and tetrabutylammonium perchlorate (TBAP; Eastman), used as received. Reagent-grade methanol (Merck) was used as the solvent in all experiments; it contained no more than $0.01 \%(\mathrm{w} / \mathrm{w})$ of water, as checked by Karl Fischer titration.

The metal salts for the complexation experiments were all of analyticalreagent grade. Calcium chloride, zinc sulphate, lead nitrate, magnesium sulphate, cobalt chloride hexahydrate (all Merck), nickel nitrate (Baker) and copper sulphate (Fluka) were used in the conductometric experiments; in the polarographic experiments, another anion was chosen for some of these metals, i.e., zinc acetate dihydrate $(\mathrm{BDH})$, magnesium chloride (Baker) or lead acetate trihydrate (UCB).

\section{Equipment}

The polarographic equipment consisted of a Metrohm E506 Polarecord with a E505 polarographic stand and was operated in the 3 electrode mode. The counter electrode was a platinum wire. The silver/silver chloride reference electrode (Metrohm EA441/5) was filled with $0.1 \mathrm{M}$ tetraethylammonium chloride in methanol. Glass capillaries from Metrohm (Type EA1019/2) 
were used for the dropping mercury electrode. The natural drop-time of these capillaries at a mercury column height of $40-50 \mathrm{~cm}$ at open circuit was 6-7 s and the mercury flow was ca. $1 \mathrm{mg} \mathrm{s}^{-1}$ in $0.1 \mathrm{M}$ TBAP in methanol. This equipment was computerized by means of a Apple IIE computer, a Digiloc (type ADC16-12/3) 12-bit A/D converter and a Kronemuis 12-bit D/A converter as described earlier [14].

For the conductivity measurements, a Philips PW9509 conductivity meter was used (accuracy, $0.15 \%$ of full-scale reading) with a Philips PW9510/60 measuring cell; the cell constant $\left(0.77 \mathrm{~cm}^{-1}\right)$ was determined with aqueous potassium chloride solutions. For the addition of titrant, a Radiometer autoburette ABU12a (total volume, 2.5 or $25.0 \mathrm{ml}$ ) was used. Additions were computer-controlled, fixed-volume increments of 0.01 or $0.100 \mathrm{ml}$. The accuracy of the burette is $0.1 \%$. The titration vessel with the conductivity cell was kept at $25.0 \pm 0.1^{\circ} \mathrm{C}$ by a Tamson thermostat. The recorder output of the conductivity meter was used for data acquisition by a Basis-108 microcomputer equipped with a 12-bit A/D converter with a $1.000-\mathrm{V}$ range (Digiloc, type ADC16-12/3).

\section{Procedures}

Conductivity measurements. The vessel was filled with a known volume of a standardized solution of a salt of the cation to be investigated. The titrant solutions were prepared by dissolving the ligands in the same salt solution as used for the starting solution in the titration vessel in order to maintain constant ionic strength. For a given system, the titrations were continued to various final metal ion/ligand concentration ratios to establish the most favourable change in conductivity to be used in the calculations. The solution was stirred magnetically.

The results were calculated with a simplex curve-fitting procedure [12] based on a 1:1 metal/ligand complex formation model and on a model also containing the $\mathrm{ML}_{2}$ complex. The second model was adopted if the first showed a characteristic "deviation plot" and a significant improvement in the fit was observed. An example of this situation is given in Fig. 1.

Sampled d.c. polarography. The polarographic cell was thermostated to $25.0 \pm 0.1^{\circ} \mathrm{C}$. Nitrogen, presaturated with methanol at this temperature, was passed for $25 \mathrm{~min}$ through the solution $\left(5 \mathrm{ml}\right.$ of $5 \times 10^{-4} \mathrm{M}$ metal ion in the relevant electrolyte) to expel oxygen. During the recording of the polarograms, the solution was blanketed with nitrogen. The polarographic half-wave potential and limiting current of the simple metal ion were measured. Complex formation was studied by stepwise addition of a concentrated solution of the crown ether ligand into the starting solution (8-10 steps) until the final concentration ratio of the ligand and metal ion reached 10:1. After each addition of ligand solution, nitrogen was bubbled through the solution for $3 \mathrm{~min}$ before the polarogram was recorded. The polarograph was operated in the d.c. Tast mode, with the drop-time set at 0.8 or $1 \mathrm{~s}$. The scan speed was $2.5,3$ or $4 \mathrm{mV} \mathrm{s}^{-1}$, depending on the polarographic 

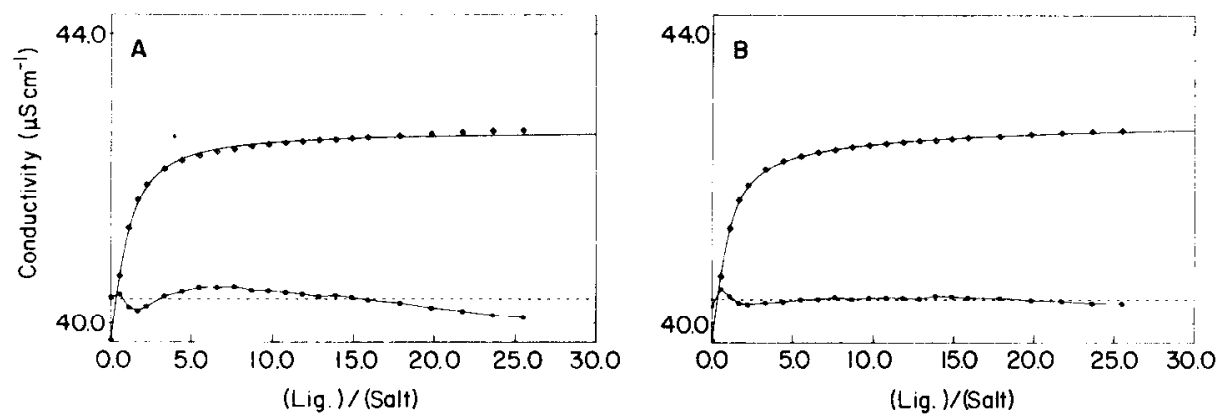

Fig. 1. Conductivity plots for $\mathrm{Ca}^{2+}\left(5 \times 10^{-4} \mathrm{M}\right) / 18 \mathrm{C} 6 /$ methanol systems: (A) with $\mathrm{ML}$ formation only; (B) with the $\mathrm{ML} / \mathrm{ML}_{2}$ model. ( $(0)$ Measurements; ( - ) calculated curve; (०) deviation plot; (- - ) zero line.

behaviour. At each step, the shift of the half-wave potential and the limiting current were measured from the polarogram.

Both the crown ether and the metal ion were dissolved in methanol containing $0.1 \mathrm{M}$ supporting electrolyte, TEAI for $\mathrm{Ca}^{2+}, \mathrm{Mg}^{2+}, \mathrm{Ni}^{2+}$ and $\mathrm{Zn}^{2+}$, and TBAP for $\mathrm{Pb}^{2+}, \mathrm{Co}^{2+}$ and $\mathrm{Cu}^{2+}$.

Half-wave potentials and limiting currents were calculated from the polarograms by the FORTH computer program described earlier [14]. Stability constants were calculated with the use of the POLAG computer program, kindly made available by Leggett [16], which was adapted for changing total metal-ion concentration.

\section{RESULTS AND DISCUSSION}

\section{Complexation behaviour of divalent cations and crown ethers}

In Table 1, the formation constants of the complexes of four crown ethers with various divalent cations are given. Generally, the data obtained from the polarographic and conductometric method agree quite well. The log $K$ values corresponding to the complexes with a $1: 1$ stoichiometry fall in the range 2.1-4.2 if the extremely high values for the complexes of $\mathrm{Pb}^{2+}$ with $18 \mathrm{C} 6$ and DC18C6 are ignored. This means that the thermodynamic stabilities of the complexes with divalent cations are low in comparison to complexes with the monovalent (alkali metal) cations. For instance, $18 \mathrm{C} 6$ forms 1:1 complexes with the alkali cations $\mathrm{Na}^{+}, \mathrm{K}^{+}, \mathrm{Rb}^{+}$and $\mathrm{Cs}^{+}$in methanol, with $\log K$ values in the range $4.3-6.2[7]$. This may be caused by the fact that the divalent cations are solvated much better than the monovalent cations [17]. On complex formation with the divalent cations, the crown ether ligand has to replace the tightly bound methanol molecules, which makes the driving force for the complexation much more entropic in nature than in the case of complex formation of monovalent cations. The delicate balance between the effects of enthalpy and entropy apparently favours the 


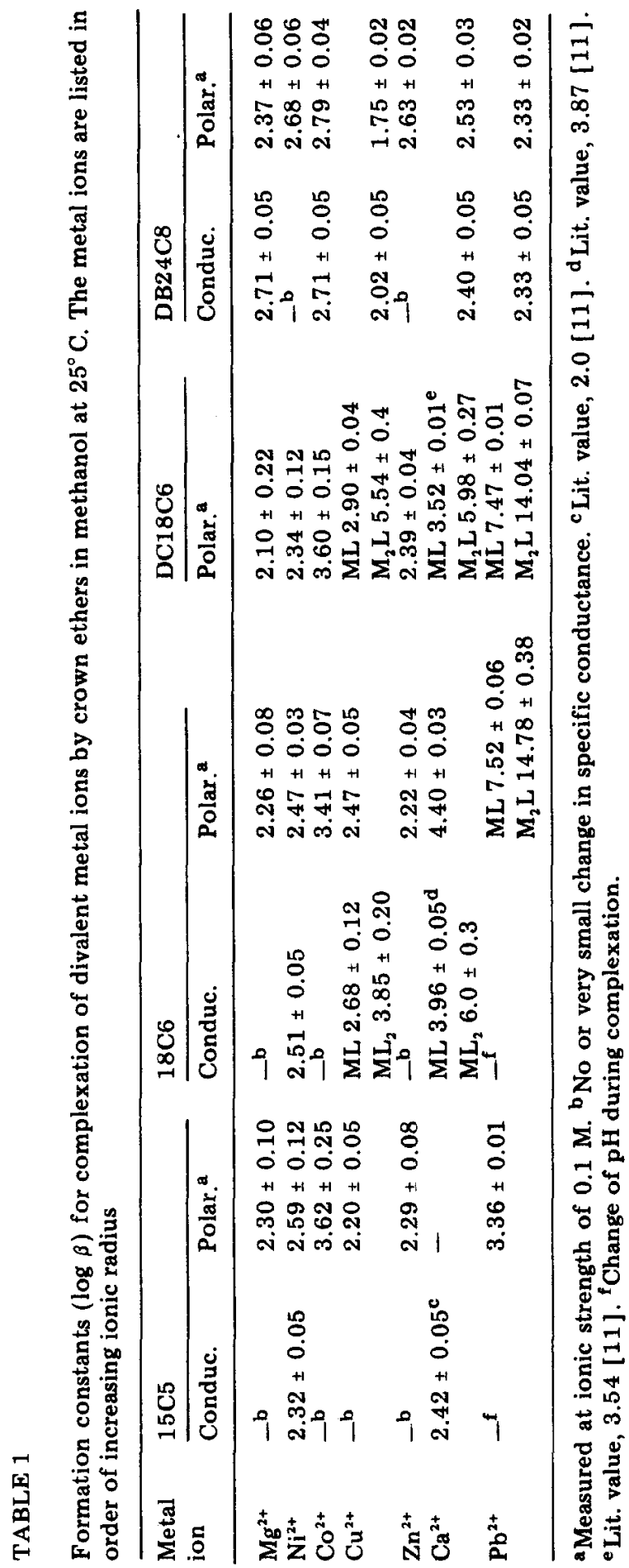


complexation of macrocyclic polyethers with monovalent cations. Unfortunately, the methods described here yield information only on the free energy of complexation.

The diameters of the $\mathrm{Ni}^{2+}, \mathrm{Co}^{2+}, \mathrm{Mg}^{2+}, \mathrm{Zn}^{2+}$ and $\mathrm{Cu}^{2+}$ ions are small (0.6$0.8 \AA$ ) compared to the hole size of the smallest ligand in this study, 15C5 $(0.8-0.9 \AA)$ [7]. The diameters of $\mathrm{Cu}^{2+}(1.00 \AA)$ and $\mathrm{Pb}^{2+}(1.19 \AA)$ are somewhat larger, and these cations form stronger complexes with $18 \mathrm{C} 6$ $(1.3-1.4 \AA)$ than with $15 \mathrm{C5}$ [7]. However, a clear relationship between cation diameter and hole size [18-20] is not observed, which is in agreement with the above comments on the role of entropy.

Complexes with a host/guest ratio of $2: 1$ were observed (in solution) for $18 \mathrm{C} 6$ with $\mathrm{Cu}^{2+}$ and $\mathrm{Ca}^{2+}$. Such complexes have been observed in the solid state for crown ethers with smaller ring sizes [7], but different stoichiometries may be found in solid state and in solution. For instance, B15C5 forms a 1:2 sandwich-type complex with potassium iodide in the solid state [21] whereas in methanol/water mixtures a $1: 1$ stoichiometry was indicated [22].

Complexes comprising a ligand with two metal cations [23] were observed in some cases (Table 1). Although many such complexes have been reported, the ligands mostly possess nitrogen, sulphur or phosphorus hetero-atoms [23]. To our knowledge, the only x-ray study of a 1:2 complex of a macrocyclic polyether having only oxygen hetero-atoms is concerned with the $1: 2$ DB24C8/potassium thiocyanate complex reported by Mercer and Truter [24].

\section{Comparison of the polarographic and conductometric methods}

The polarographic method was more generally applicable than the conductometric method. This is due to the fact that it is based on the measurements of two separate effects caused by complexation, the change of the half-wave potential and the change in the diffusion current. It is sufficient that only one of the two effects is present to be able to follow complexation by this technique. The polarographic method failed only for one of the systems investigated; in the calcium chloride/15C5/0.1 M TEAI system in methanol, a polarographic maximum developed on addition of the $15 \mathrm{C5}$ ligand. A second advantage of the polarographic method in comparison to the conductivity method is that it is insensitive to the presence of small amounts of ionic impurities in the crown ethers. A third advantage is its ability to deal with the occurrence of species other than $M L$ and $M L_{2}$. The conductometric method in its present form cannot easily be extended to include species like $\mathrm{M}_{2} \mathrm{~L}$ because the ionic strength changes if this type of complex is formed. A curve-fitting procedure for this situation should include the two constants from the Onsager equation for each ionic species, which makes the total number of parameters to be fitted too large for practical use.

In a significant number of cases, evaluation of the polarographic data with the Leggett [16] program showed a better fit if the $M_{2} L$ species was included in the model. However, results were accepted only if the sum of the squared 
errors improved significantly on the inclusion of the $M_{2} L$ species without impairing the error in the $\log K$ value. An example of a data set illustrating such a situation is given in Table 2.

With regard to the missing entries under the conductometric method in Table 1, either there was no change in the specific conductance on addition of the ligand or the polarographic experiments indicated $\mathrm{M}_{2} \mathrm{~L}$ formation. Observations of the first category are in agreement with those from polarography in as much as no change in the diffusion current constant was observed when ligand was added. For the second category, the evaluation of the conductometric experiments, based on the $\mathrm{ML}$ or $\mathrm{ML} / \mathrm{ML}_{2}$ model only, was obviously incorrect and produced $\log K$ values that deviated significantly from those obtained by polarography. Generally, this situation can be recognized early by the larger values of the sum of the squared errors that are obtained in the curve-fitting procedure for these cases. For DC18C6, no reliable conductometric results could be obtained, because of the presence of a minor acidic impurity.

The systems $15 \mathrm{C5} / \mathrm{Pb}^{2+}, 18 \mathrm{C} 6 / \mathrm{Pb}^{2+}$ and $\mathrm{DC} 18 \mathrm{C} 6 / \mathrm{Pb}^{2+}$ behaved differently from the other systems investigated. In the polarographic experiments, the diffusion current constant of the waves did not change significantly, which means that the diffusion constants of the free lead ion and its complexes have about the same magnitude. During the conductometric titrations, however, the conductance changed considerably on addition of the ligands. As this cannot be attributed to a difference in the equivalent conductances of the free metal ion and its complexes, a possible explanation was sought in the occurrence of acid/base reactions accompanying the complexation reaction. Indeed, an increase of $\mathrm{pH}$ was found during the titration of lead(II) ion with 18-crown-6, which completely invalidates the evaluation method for the conductivity measurements of these systems. To test the influence of $\mathrm{pH}$ on the complexation of lead(II) in the polarographic method, the system lead(II)/ 18-crown- 6 was rerun with $0.01 \mathrm{M}$ perchloric acid added to the supporting

TABLE 2

Polarographic data for the system $\mathrm{Pb}^{2+} /$ dicyclohexyl-18-crown-6/0.1 M TBAP/methanol

\begin{tabular}{llllllll}
\hline $\begin{array}{l}\text { Ligand } \\
\text { conc. } \\
\left(10^{-3} \mathrm{M}\right)\end{array}$ & $\begin{array}{l}\text { Lead(II) } \\
\text { conc. } \\
\left(10^{-3} \mathrm{M}\right)\end{array}$ & $\begin{array}{l}E_{1 / 2} \\
(\mathrm{~V})\end{array}$ & $\begin{array}{l}\text { Limiting } \\
\text { current } \\
(\mu \mathrm{A})\end{array}$ & $\begin{array}{l}\text { Ligand } \\
\text { conc. } \\
\left(10^{-3} \mathrm{M}\right)\end{array}$ & $\begin{array}{l}\text { Lead(II) } \\
\text { conc. } \\
\left(10^{-3} \mathrm{M}\right)\end{array}$ & $\begin{array}{l}E_{1 / 2} \\
(\mathrm{~V})\end{array}$ & $\begin{array}{l}\text { Limiting } \\
\text { current } \\
(\mu \mathrm{A})\end{array}$ \\
\hline- & 0.500 & -0.3038 & 1.290 & 2.830 & 0.472 & -0.4470 & 1.201 \\
0.980 & 0.490 & -0.4300 & 1.211 & 3.704 & 0.463 & -0.4511 & 1.181 \\
1.456 & 0.485 & -0.4377 & 1.217 & 4.128 & 0.459 & -0.4532 & 1.181 \\
1.923 & 0.480 & -0.4412 & 1.211 & 4.546 & 0.455 & -0.4551 & 1.178 \\
2.381 & 0.476 & -0.4442 & 1.202 & & & & \\
\hline
\end{tabular}

Model: $M+L=M L$ and $2 M+L=M_{2} L . \log K_{M L}=7.46 \pm 0.01, \log \beta_{M_{2} L}=14.2 \pm$ 0.1 , sum of square errors $=1.9 \times 10^{-6}$.

Model: $M+L=M L . \log K=7.50 \pm 0.02$, sum of square errors $=1.2 \times 10^{-5}$. 
electrolyte. The results were not significantly different from the values obtained in the neutral supporting electrolyte: $\log K_{\mathrm{ML}}=7.91$ and $\log \beta_{\mathrm{M}_{2} \mathrm{~L}}$ $=16.00$.

For the system $15 \mathrm{C} 5 / \mathrm{Cu}^{2+}$, the conductometric method indicated $\mathrm{ML}_{2}$ formation. This was not confirmed by the polarographic results. Apparently, the conductometric method is more sensitive in distinguishing the occurrence of $\mathrm{ML}_{2}$ formation.

\section{Conclusions}

The results described show that macrocyclic polyethers form complexes with divalent cations in polar media. The combination of polarographic and conductometric methods for the determination of stability constants gives an accurate indication of the thermodynamic stabilities of the complexes formed. For the proposed application, i.e., using ligands with a cocomplexed electrophile for the complexation of neutral molecules, the stabilities of the complexes are too low. Clearly, for the formation of more stable complexes, functionalized macrocyclic polyethers are required; these will be described elsewhere.

\section{REFERENCES}

1 V. M. L. J. Aarts, J. Geevers, D. N. Reinhoudt, W. Lengton, M. Bos, J. W. H. M. Uiterwijk and S. Harkema, Tetrahedron, 43 (1987) 617.

2 P. D. J. Grootenhuis, J. W. H. M. Uiterwijk, D. N. Reinhoudt, C. J. van Staveren, E. J. R. Sudhölter, M. Bos, J. van Eerden, W. T. Klooster, L. Kruise and S. Harkema, J. Am. Chem. Soc., 108 (1986) 780.

3 J. A. A. de Boer, D. N. Reinhoudt, S. Harkema, G. J. van Hummel and F. de Jong, J. Am. Chem. Soc., 104 (1982) 4073.

4 C. J. van Staveren, V. M. L. J. Aarts, P. D. J. Grootenhuis, J. van Eerden, S. Harkema and D. N. Reinhoudt, J. Am. Chem. Soc., 108 (1986) 5271.

5 V. M. L. J. Aarts, C. J. van Staveren, P. D. J. Grootenhuis, J. van Eerden, L. Kruise, S. Harkema and D. N. Reinhoudt, J. Am. Chem. Soc., 108 (1986) 5035.

6 F. A. Cotton and A. Wilkinson, Advanced Inorganic Chemistry, 4 th edn., Wiley, New York, 1980.

7 R. M. Izatt, J. S. Bradshaw, S. A. Nielsen, J. D. Lamb and J. J. Christensen, Chem. Rev., 85 (1985) 271.

8 R. M. Izatt, D. P. Nelson, J. H. Rytting, B. L. Haymore and J. J. Christensen, J. Am. Chem. Soc., 93 (1971) 1619.

9 R. M. Izatt, R. E. Terry, B. L. Haymore, L. D. Hansen, N. K. Dalley, A. G. Avondet and J. J. Christensen, J. Am. Chem. Soc., 98 (1976) 7620.

10 R. M. Izatt, R. E. Terry, D. P. Nelson, Y. Chan, D. J. Eatough, J. S. Bradshaw, L. D. Hansen and J. J. Christensen, J. Am. Chem. Soc., 98 (1976) 7626.

11 H. H. Buschmann, Chem. Ber., 118 (1985) 2746.

12 D. Ph. Zollinger, Ph.D. Thesis, Twente University of Technology, 1986.

13 D. Ph. Zollinger, M. Bos, A. M. W. van Veen-Blaauw and W. E. van der Linden, Anal. Chim. Acta, 161 (1984) 83.

14 D. Ph. Zollinger, M. Bos, A. M. W. van Veen-Blaauw and W. E. van der Linden, Anal. Chim. Acta, 167 (1985) 89.

15 H. S. Gold and M. R. Rice, Talanta, 29 (1980) 637.

16 D. J. Leggett, Talanta, 27 (1980) 787. 
17 Y. Marcus, Ion Solvation, Wiley, Chichester, 1985.

18 G. W. Gokel, D. M. Goli, C. Miganti and L. Echegoyen, J. Am. Chem. Soc., 105 (1983) 6786.

19 P. D. J. Grootenhuis, P. D. van der Wal and D. N. Reinhoudt, Tetrahedron, 43 (1987) 397.

20 F. de Jong and D. N. Reinhoudt, Adv. Phys. Org. Chem., 17 (1980) 279.

21 P. R. Mallinson and M. R. Truter, J. Chem. Soc., Perkin Trans. 2, (1972) 1818.

22 J. D. Lamb, R. M. Izatt, C. S. Swain, J. S. Bradshaw and J. J. Christensen, J. Am. Chem. Soc., 102 (1980) 479.

23 C. J. van Staveren, D. N. Reinhoudt, J. van Eerden and S. Harkema, J. Chem. Commun., (1987) 974 , and references cited therein.

24 M. Mercer and M. R. Truter, J. Chem. Soc., Dalton Trans., (1973) 2469. 